LA $-10108-215$

DEC5 001527

\title{
Design and Construction Details of the FRX-C/T Device: A Compact Toroid Plasma Translation Experiment
}

\author{
D. J. Rej
}

\begin{abstract}
DISCLAIMER
This refort was prepared as an account of work sponsored by an agency of the United States Government. Neither the United States Government nor any agency thereof, nor any of their employees, makes any warranty, express or implied, or assumes any legal liability or responsibility for the accuracy, completeness, or usefulness of any information, apparatus, product, or process disclosed, or represents that its use would not infringe privately owned rights. Reference herein to any specific commercial product, process, or service by trade name, trademark, manufacturer, or otherwise does not necessarily constitute or imply its endorsement, recommendation, or favoring by the United States Government or any agency thereof. The viev s and opinions of authors expressed herein do not recessarily state or reflect those of the United States Government or any agency thereof.
\end{abstract}

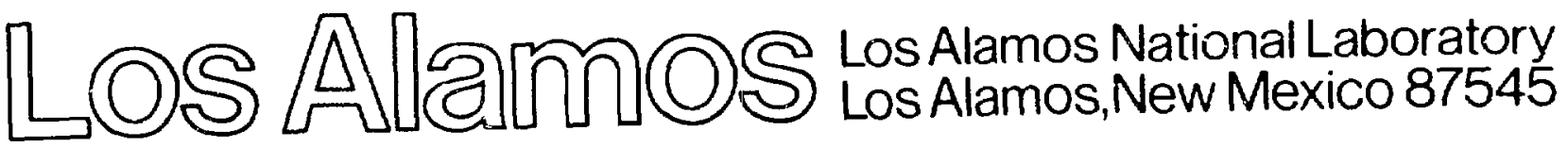




\section{CONTENTS}

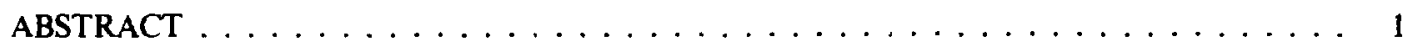

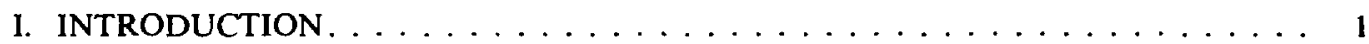

II. dc MAGNET SYSTEM $\ldots \ldots \ldots \ldots \ldots \ldots \ldots \ldots \ldots \ldots$

III. VACUUM HARDWARE $\ldots \ldots \ldots \ldots \ldots \ldots \ldots \ldots \ldots$

ACKNOWLEDGMENTS $\ldots \ldots \ldots \ldots \ldots \ldots \ldots \ldots \ldots \ldots$

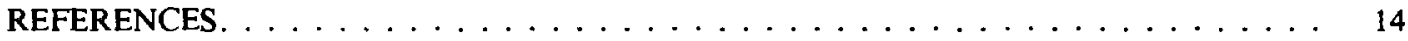

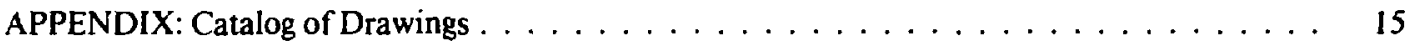




\title{
DESIGN AND CONSTRUCTION DETALLS OF THE FRX-C/T DEVICE: A COMPACT TOROID PLASMA TRANSLATION EXPERIMENT
}

\author{
by
}

D. J. Rej

\begin{abstract}
The engineering design and construction details for the compact toroid plasma translation experiment $\mathrm{FRX}-\mathrm{C} / \mathrm{T}$ are reviewed. A translation region consisting of a 0.4-m-i.d., up to 6-m-long metallic vacuum chamber has been added onto one end of the field-reversed theta-pinch device FRX-C.A 2.5-MW, dc-powered, water-cooled solenoid magnet produces an axial magnetic field of up to $10 \mathrm{kG}$ in this region. A complete directory of all related engineering drawings is also included.
\end{abstract}

\section{INTRODUCTION}

During 1983, the field-reversed configuration (FRC), magnetic fusion experiment FRX- $\mathrm{C}^{1}$ was modified to enable the study of axial translation of hot, compact toroid plasmas. (The FRX-C device is operated by CTR Division at Los Alamos National Laboratory and is located in Building SM-105, Room 189.) In the new experiment, renamed FRX-C/T, plasmas are launched out of a slightly conical theta-pinch coil into a translation region consisting of a metallic vacuum chamber and a dc magnetic guide field. ${ }^{2} A$ schematic diagram depicting the initial configuration of this new apparatus is shown in Fig. 1. A photograph of the experiment appears in Fig. 2.

This report documents the design and construction details of the FRX-C/T experimental hardware. The theta pinch and its associated high-voltage technology have been described elsewhere; ${ }^{1,3,4}$ therefore, only the modifications associated with the translation experiment are reported. This report is divided into two major parts, corresponding to the dc magnetic field and the vacuum hardware systems. A listing of all related engineering drawings appears in the Appendix.*

*Drawings available from D. J. Rej, Group CTR-3, Los Alamos National Laboratory.

\section{II. dc MAGNET SYSTEM}

Th: translation region can be up to $6 \mathrm{~m}$ long and consists of an axial guide magnetic field, $B_{2} \leq 10 \mathrm{kG}$. This field is generated by a set of water-cooled pancake coils energized by a $2.5-\mathrm{MW}$ dc power supply.

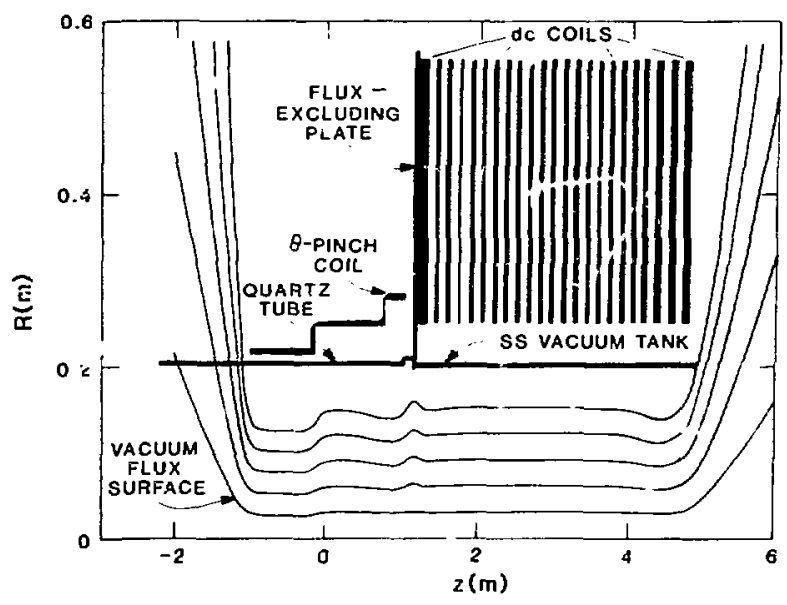

Fig. 1. Schematic diagram depicting the initial configuration of the FRX-C/T device. 


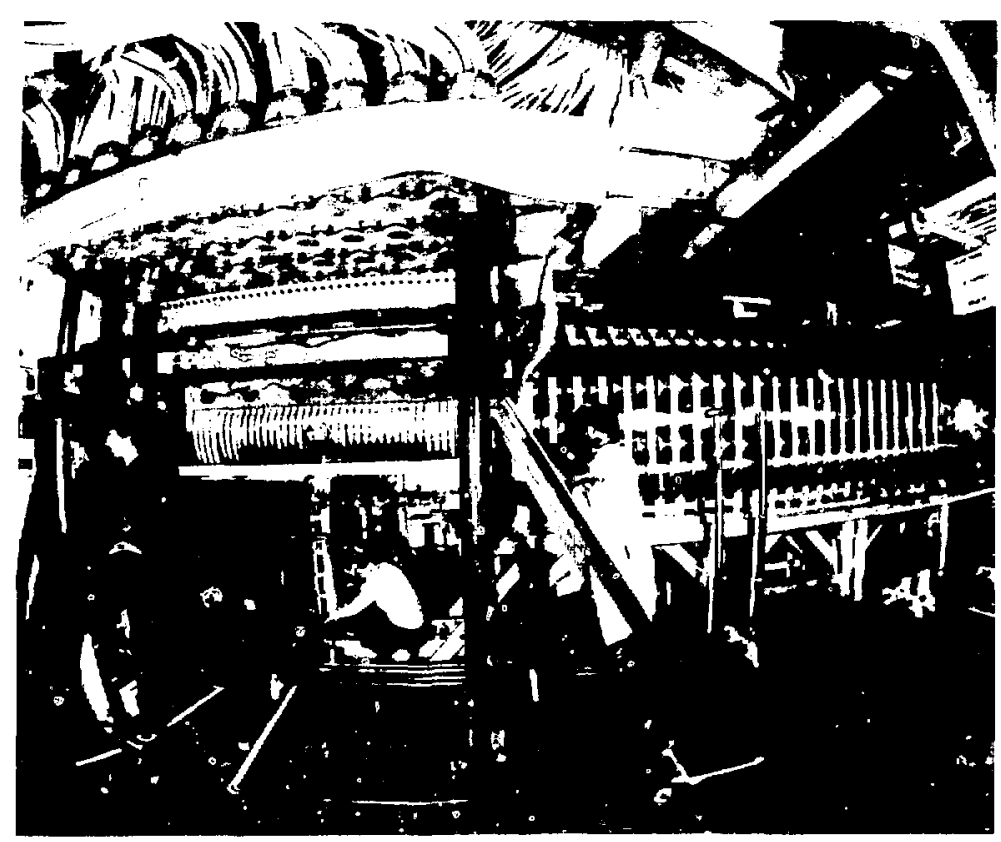

Fig. 2. Wide-angle "fish-eye" photograph of the FRX-C/T experiment.

\section{A. Magnet Coils}

The guide field is produced by a set of up to 42 "panca'ce" magnets. Each pancake (see Fig. 3) consists of two separat: i6-turn coils. The dimensions of a pancake are 20-in. i.d., 43-in. o.d., 1.625 in. wide. These magnets were built about 1963 by Pacific Electric Motor, Oakland. California. and were used in Q-machine experiments operated by the CTR-1 Group between 1969 and $1981 . .^{5}$ There are no known original drawings of these coils; however, a drawing has recently been made (Los Alamos Dwg. No. 33Y180762) from an existing pancake for the purpose of procuring new coils, and it does include the following minor deviations from the existing coil seıs: (1) more nearly standard pipe fittings for cooling hose connections, (2) fiber glass reinforcement, (3) Kapton insulation, and (4) fiber glass straps.

These magnets are water-cooled. The deionized cooling water passes through a 0.375 -in.-diam hole that passes through the $0.62^{\leftarrow}$-in. $x 0.625$-in.-square crosssection copper conductor that forms the coil. The elcctrical resistance of each 16-turn coil is approximately $3.6 \mathrm{~m} \Omega$. The two coils are wound intertwined. The windings are wrapped with a cloth insulation and the pancake is impregnated in an epoxy. No documentation of the high-voltage insulation properties for these coils could be found; moreover, no experimental high-voliage tests have been performed, in view of the high replacement cost (about $\$ 10,000$ ) of a pancake shouid one be destroyed. Instead, the design philosophy has been to adequately shield these magnets to prevent induction of any high voltage (see Sec. II.D).

Of the magnets used in the experiment, there are two different sets of pancakes. The coil parameters are essentially the same for both sets; however, for the same voltage polarity across the coil terminals, the direction of the current through the windings (or the polarity of the B-field) in one set is opposite that of the other. (The olvicus physical difference between these two sets is the shape of the top of the epoxy casting. One set has a pointed top while the other has a flat, chamfered top.)

The initial dc coil configuration (Fig. 1) consists of 28 pancakes spanning a 4-m length. A 17-cm gap separates the high-voltage, pulsed theta-pinch coil and the dc coil set. Three pancakes are placed next to one another at the theta-pinch end. Next to these coils are 19 single pancakes evenly spaced $15.2 \mathrm{~cm}$ apart. At the downstream end, a dc mirror B-field is generated by three pairs of pancakes. A central $B_{2}$-field of $2.6 \mathrm{G} / \mathrm{A}$ of coil current is produced. Typical vacuum flux surfaces and axial Bfield profile generated by the present configuration of coils have been calculated and are plotted in Figs. 1 and 4 , respectively.

The dc magnetic field axial profiles are measured using a Hall probe $(\mathrm{F}$. W. Bell, Model No.81 IAB controller and No. ZOB-8-3208 three-axis probe). A motordriven, cantilevered arm has been built (Los Alamos 


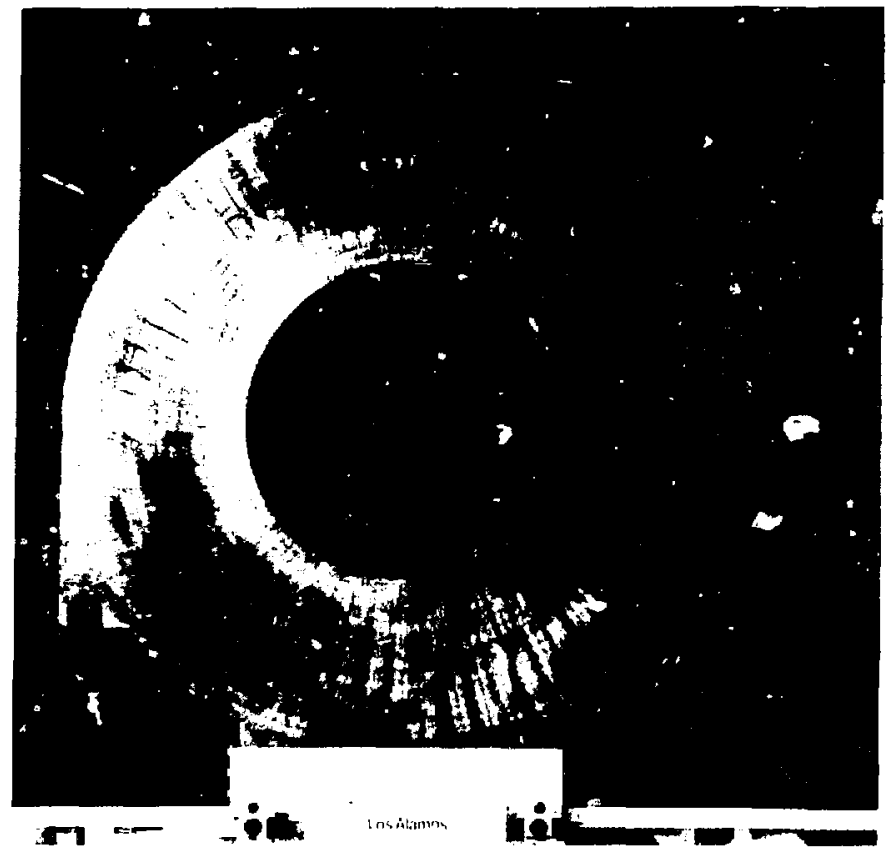

Fig. 3. Photograph of one of the pancake magnet coils used to generate the translation region guide field.

Dwg. Nos. 33Y180823 and 33Y!80852) to hold the Hall probe and automatically traverse the entire translation region length in approximately $1 \mathrm{~min}$. The probe output is recorded using a LeCroy 8210 digitizer and is stored in the FRX-C/T Prime 400 computer. A sample measured $\mathrm{dc} \mathrm{B}_{\mathrm{z}}$-field profile is displayed in Fig. 5. The rise and falltimes of the dc coil power supply are each approximately $1 \mathrm{~min}$ (see Sec. II.B). During normal operation, the dc magnets are energized simulta-

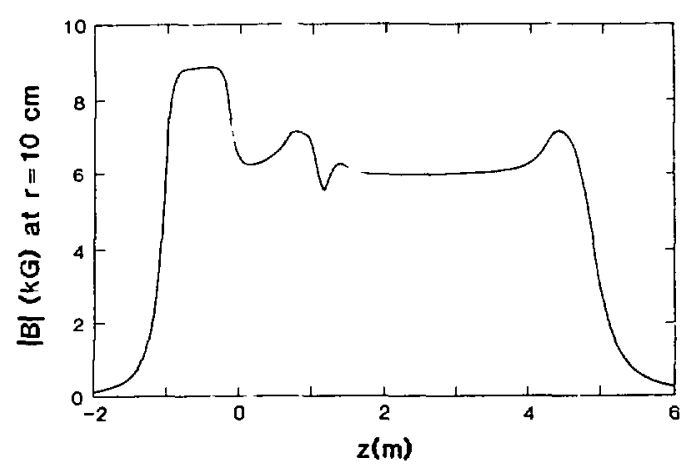

Fig. 4. Magnitude of the vacuum magnetic field at radius $r$ $=10 \mathrm{~cm}$ calculated as a function of axial position. The pulsed theta-pinch coil is centered at position $\mathrm{z}=0$. The $\mathrm{dc}$ coils are located between axial positions $\mathrm{z}=1.2$ and $4.8 \mathrm{~m}$ (see also Fig. 1). neously with the charging of the high-voltage, thetapinch coil capacitor banks. Following the plasma discharge (which lasts less than $1 \mathrm{~ms}$ ), the dc power is ramped down to a minimum power level of about $3 \mathrm{~kW}$.

Vacuum field perturbations caused by ferromagnetic materials (e.g., bearing shafts, conduits, steel I-beams, deck plates, stainless steel welds) surrounding the dc coils have been measured and they were found to be a few gauss. Plotted in Fig. 6 are axial $B_{z}$ profiles with the

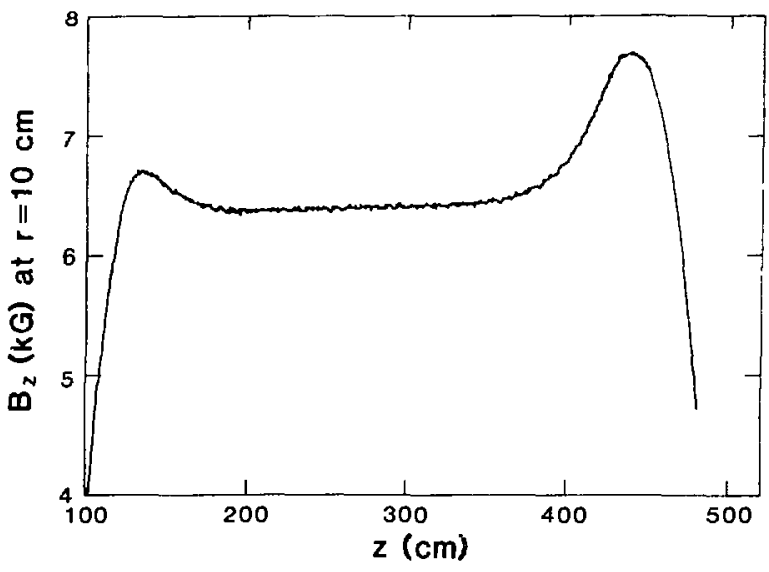

Fig. 5. Axial profile of the dc $B_{z^{-}}$-field at radius $10 \mathrm{~cm}$. These measurements were made with a Hall probe. 

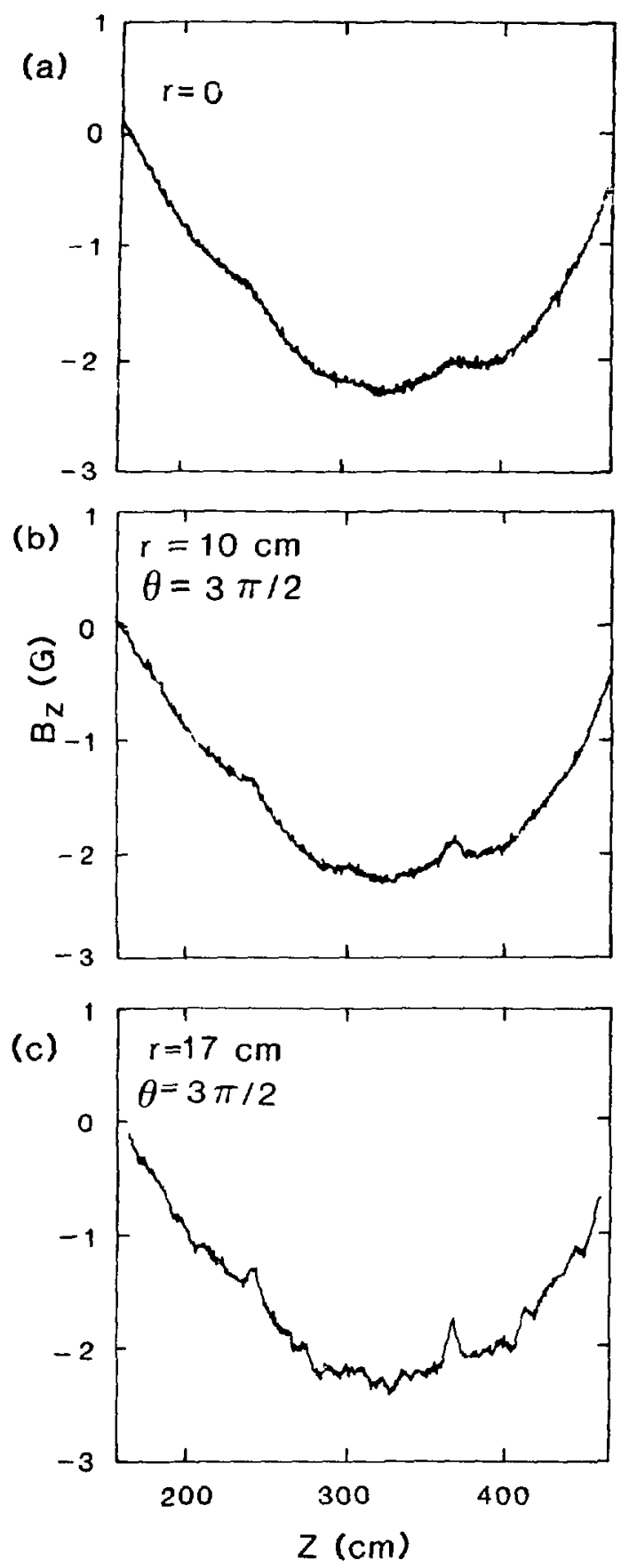

Fig. 6. Typical stray $B_{z}$-fields created by the magnetized objects surrounding the experiment. Axial profiles of $B_{\mathbf{z}}$ were measured at radii (a) 0 , (b) 10 , and (c) $17 \mathrm{~cm}$. These Hall probe measurements were made after the magnets were energized to near full power. dc power turned off for radii of (a) 0 , (b) 10 , and (c) $17 \mathrm{~cm}$. These measurements were made after the coils have been energized to produce a $7.5-\mathrm{kG}$ field. The $B_{r}$ and $B_{v}$ components are of the same magnitude as (but always less than) $B_{z}$. The primary source of these stray fields appears to be the galvanized steel diagnostic conduits that pass directly over the translation region and are routed to the CTX experiment. The 0.5-G fine structure in the axial $B_{2}(z)$ profile at $17-\mathrm{cm}$ radius results from magnetized stainless steel welds in the vacuum chamber that became ferromagnetic from the welding process (see Sec. III.A).

\section{B. dc Power System}

The magnet coils are energized using a 12-phase, 2.5-MW dc power supply manufactured in 1960 by the ITE Circuit Breaker Co., Philadelphia, Pennsylvania. This apparatus has been used in the CTR-1 Q-machine experiments. ${ }^{5.6} \mathrm{~A}$ detailed description of this power supply and its associated control, cooling, and safety systems is available from Rita Gribble, Los Alamos Group CTR-3. The supply output can be varied from 72 $\mathrm{kA}$ at $35 \mathrm{~V}$ to $9 \mathrm{kA}$ at $280 \mathrm{~V}$. The latter combination is used in FRX-C/T experiments to minimize resistive losses in the busbar feeds (see bclow). The rise and falltimes of the dc output are limited to approximately 1 min by the power supply inductrol voltage regulator.

The power supply is located outside the south wall of Building SM-105, Room 180. The output penetrates this wall and is connected to the FRX-C/T magnet coils by a pair of busbars (Los Alamos Dwg. No. 33Y 180800) approximately $100 \mathrm{ft}$ long that runs between Rooms 180 and 189. In Room 180, a busbar interface exists where the dc power can be diverted from the FRX-C/T device to the EMET project operated by the CTR-4 Group. The busbars are made of either 1.625-in. x 10-in. crosssection, type 6101 aluminum or 1.75 -in. $\times 10$-in. crosssection, type 6061 aluminum. The busbar sections range up to $12 \mathrm{ft}$ in length and are joined together by welds or by 0.375 -in.-thick copper plates bolted to the aluminum bars. A conducting grease (Catalog No. 21059, manufactured by Thomas and Betts Co., Raritan, New Jersey) is used at these junctions tis minimize the electrical resistance. The total electrical resistance of the busbars is approximately $0.2 \mathrm{~m} \Omega$. At full power, the corresponding resistive loss in the busbars is $16 \mathrm{~kW}$. A high-power, "free-wheeling" diode (Westinghouse Model No. RA200648, 600-V reverse voltage, 4.8-kA dc forward current) is installed in reverse polarity across the busbars in Room 180 and conducts the total load 
current in case of a sudden power loss. The decay time of the current in this situation is limited by the $L / R$ (load inductance/load resistance) time and is about $0.3 \mathrm{~s}$.

The load consists of two or three parallel legs, each leg consisting of up to 15 pancake magnets (i.e., 30 coils) connected in series. The current in each leg may be adjusted to within $\pm 5 \%$ using a water-cooled, $0-10-\mathrm{m} \Omega$ variable shunt resistor (Los Alamos Dwg. No. 33 Y 180801) that is connected in series with each leg. Each connection between the busbars and the load is made using five parallel $4 / 0$ welding cables. In addition to their existing insulation, these cables are wrapped with 0.375 in. of polyethylene (Bishop biseal tape No. 3) and are shielded using a grounded braid.

Series electrical connections between coils within a single pancake are made usili: 0.25 -in.-thick, annealed copper plates approximately $4 \mathrm{in}$. high and $1.5 \mathrm{in}$. wide. Connections between adjacent pancakes are typicaily made using 0.25 -in. x 4.5-in. x 5.5-in. copper plates.

The total busbar current is measured indirectly using a magnetic Hall probe (Micro Switch Model No. 91SS12-2) mounted between the busbars. The bus voltage is also measured with a high-resistance voltage divider. Voltage and current isolation of these monitors is obtained using battery-operated fiberoptic transceivers (Los Alamos Dwg. No. 45Y 123941).

The potential electrical hazards involving the entire dc power system are reviewed in the Standard Operating Procedure submitted by CTR-3 to Los Alamos HSE
Division in August 1983.* For safety purposes, the busbars are entirely enclosed by an electrically grounded metallic cladding. The busbars are supported by phenolic blocks, and a gap of at least 2 in. separates the bars from the cladding. Most of the cladding consisis of perforated steel or aluminum sheets. In the experimental area, 0.5 -in.-thick aluminum plates are used to better shield the busbars against induced voltages.

\section{Cooling Systems}

The two independent water-cooling systems in FRX$\mathrm{C} / \mathrm{T}$ are used for the 2.5-MW dc power supply and for the magnets. A description of the power supply cooling system is available from Rita Gribble, Los Alamos Group CTR-3.

Because of the nominal 1-min risetime for the dc power, a dc magnet cooling system is necessary. A schematic diagram of the FRX-C/T magnet cooling system appears in Fig. 7. Some of this equipment has been used previously in the CTR-1 Q-machine experiments. Water is forced through this closed loop at head pressure of up to $300 \mathrm{psi}$ and flow rate of $350 \mathrm{gal} . / \mathrm{min}$ using a pump powered by a 100-HP motor. This pump and its electrical systems are located in SM-163.

*Unpublished (available from D. J. Rej, Group CTR-3, Los Alamos National Laboratory).

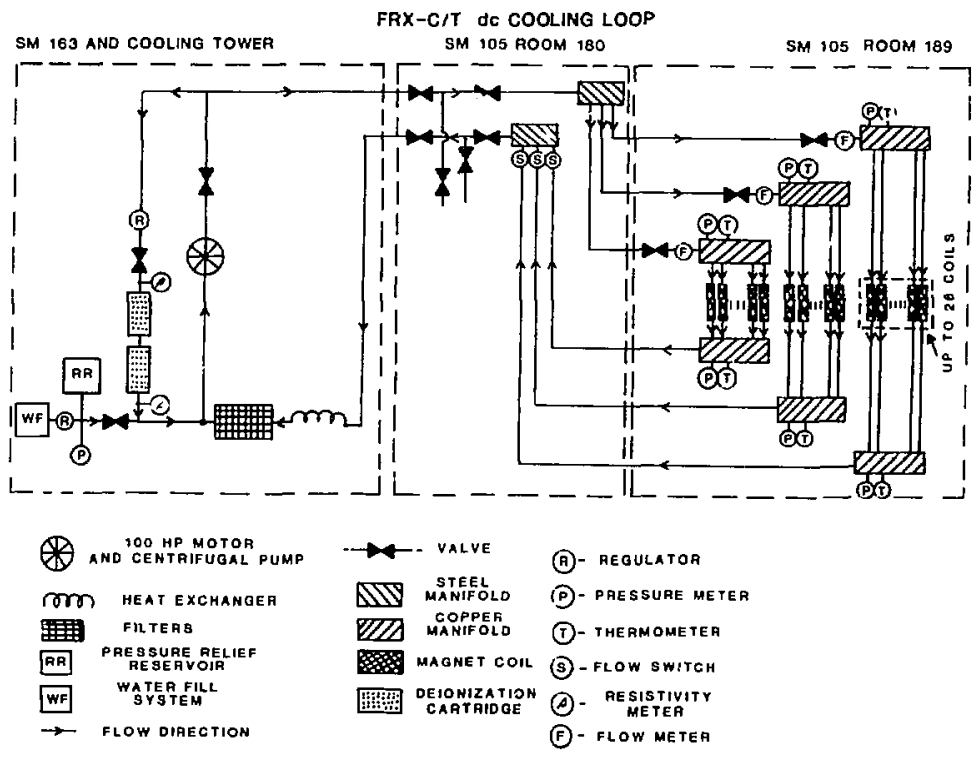

Fig. 7. Schematic diagram of the FRX-C/T de magnet cooling system. 
The water is pumped underground through 4-in.-i.d. schedule 80 steel pipe into SM-105 Room 180 . The most economical method of bringing this water to the magnets in Room 189 uses three parallel hydraulic hoses (Aeroquip Model No. 2580-32: 1.81-in. i.d., 2.22-in. o.d., 350-psi working pressure, 1400-psi burst pressure, 13.25 -in. minimum bending radius). The hose lengths range between 100 and $125 \mathrm{ft}$. The combined pressure drop across the three supply and three return hoses is about $31 \mathrm{psi}$ for $330 \mathrm{gal} . / \mathrm{min}$. These hoses are connected at one end through steel manifolds to the supply and return 4-in. pipes in Room 180 and at the other end to copper manifolds in Roonı 189 (Los Alamos Dwg. No. 33Y180805).

The flow through each supply copper manifold can be adjusted using a valve located at the inlet. The flow rate in each is monitored using a Venturi-type flow meter (RCM Industries, Orinda, California, Model No. 2-71$\mathrm{R}-200-\mathrm{H}$ ). Pressure gauges and thermometers are also mounted on each copper manifold. The remaining twenty-eight 0.5 -in. NPT fittings in each copper manifold are connected to the magnet coils using nominally 5-ft-long hydraulic hoses (Weatherhead Model No.HIOI 10: 0.625-in. i.d., 0.906-in. o.d., 250-psi working pressure, 1000-psi burst pressure, nonconducting). "Quick disconncct" fittings (Snap Tite Inc., Model No. BVHN 8-8-F and No. BVHC 8-8-F) are used to connect the hoses to the manifold. (The entire hose assembly is sketched in Los Alamos Dwg. No. 33Y180803.) All fittings are made from brass with the exception of the steel bearings inside the quick disconnect fittings.

The dc magnet coils are all cooled in parallel. Figure 8 plots the calculated pressure drop $\Delta \mathrm{P}$ as a function of water flow rate through each approximately 130 -ft-long coil conductor. Typical operating values are $\Delta \mathrm{P}=$ $128 \mathrm{psi}$ at $4.3 \mathrm{gal} . / \mathrm{min}$ per coil. At steady-state conditions with a $2.7-\mathrm{kA}$ coil current, the return water temperature is about $14^{\circ} \mathrm{C}$ warmer than the supply water temperature. The observed time-dependent . sturn water temperature for a $2.7-\mathrm{kA}$ coil current applied for about $3 \mathrm{~min}$ is plotted in Fig. 9.

The magnet coils are also protected against overheating by the following methods: (1) The 100-HP pump is interlocked such that when turned off, the FRX-C/T Prime 300 control computer system issues an abort to the power supply. This abort decreases the power le, el to the safe minimum value. (2) Similar aborts are actuated by flow switches (Harwil Corp., Santa Monica, California, Model No. Q-5/3/H/-A) mounted on the inlets of the return manifold in Room 180 (see Fig. 7). (3) A thermistor system* has been built to monitor individual coil temperatures. (4) The temperature of each coil is also monitored by two precision thermostats

*Information available from Rita Gribble, Los Alamos Group CTR-3.

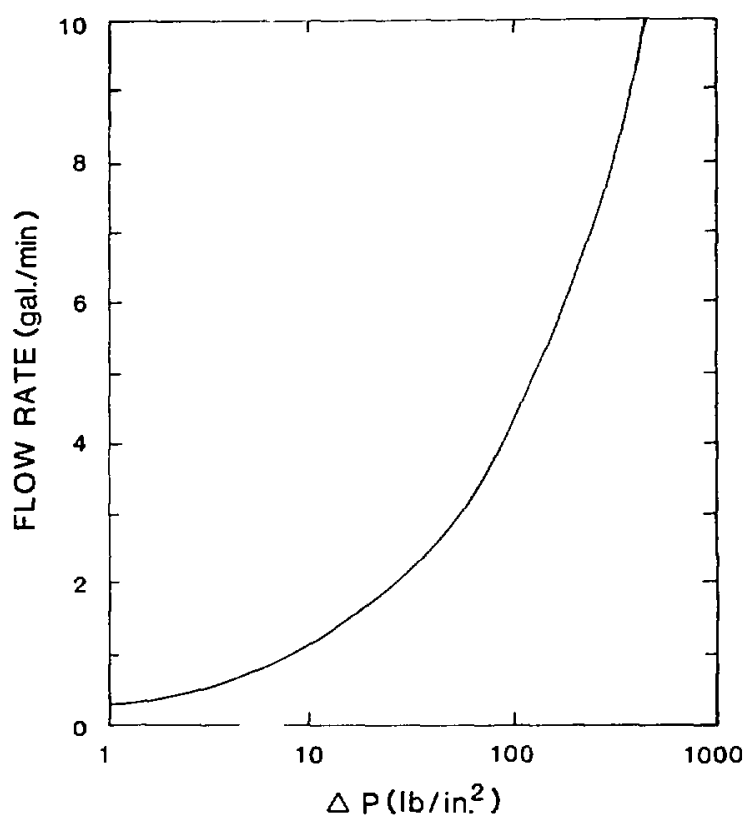

Fig. 8. Water flow rate through a single magnet coil calculated as a function of the pressure drop across the coil.

(Klixon Model No.C4344144). When a coil temperature $T_{c}$ exceeds $66^{\circ} \mathrm{C}$, a warning message is immediately sent by the computer to the machine operator. When $T_{c}$ exceeds $79^{\circ} \mathrm{C}$, an abort signal is sent to the power supply.

In SM-163, the cooling water also passes through deionization cartridges placed in a parallel loop directly across the pump. The water resistivity $\rho_{w}$ is monitored at the cartridge inlet and outlet. Typical $\rho_{w}$ values are 0.80 and $>18 \mathrm{M} \Omega \cdot \mathrm{cm}$ at the inlet and outlet, respectively.

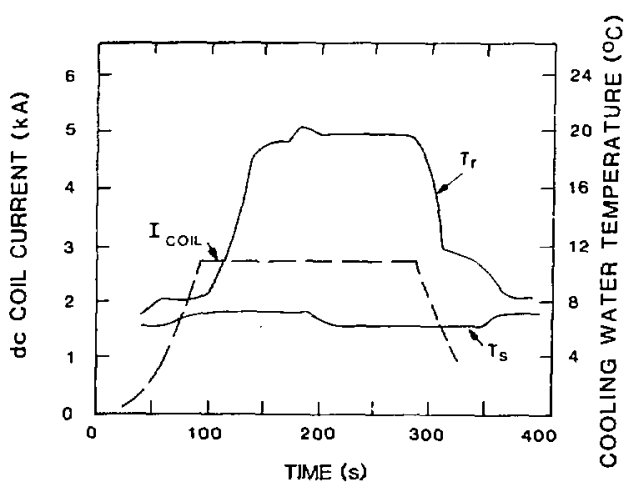

Fig. 9. Water temperature rise of the supply and return magnet cooling lines, $T_{s}$ and $T_{r}$, measured as a function of time. A peak dc current of $2.7 \mathrm{kA}$ was applied for approximately $3.3 \mathrm{~min}$ to each coil. 
The return water from the magnet coils passes through a heat exchanger located in the cooling tower adjacent to SM-163. The tower is cooled by water circulated from a sump and is also air-cooled by a pair of two-speed 8-ft-diam fans. All of these components are operated either manually from switches located in SM-163 or automatically using a Johnson step controller which maintains a preset supply-water temperature.

The busbars are currently not water-cooled. Because of the busbar mass, the rate of temperature rise is quite low, even at full power. Current operation requires a duty cycle less than $5 \%$ (for full power operation). Ambient air cooling between shots is adequate. If, however, dc operation over intervals greater than about $\mathrm{l} \mathrm{h}$ uecomes desirable, some slight modifications will be necessary. The temperature rise in the type $6101 \mathrm{Al}$ busbars, in the absence of any cladding, has been calculated. The ohmic power dissipated by the bars heats the aluminum while heat is lost by air convection and radiation to the room. The results from these calculations are plotted in Fig. 10 for a busbar current of $7.5 \mathrm{kA}$ and radiative emissivities of 0.028 and 0.5 . The former value corresponds to present conditions, whereas the latter value might be achieved if one were to paint the busbars black. The temperature rises from room temperature to $: 15^{\circ} \mathrm{C}$ and $75^{\circ} \mathrm{C}$, respectively, requiring approximately $4 \mathrm{~h}$ to reach these steady-state values. Air convection cooling is ineffective for the busbars surrounded by the solid Al plate cladding. These busbars, however, contain two 0.5 -in.-i.d. holes bored through

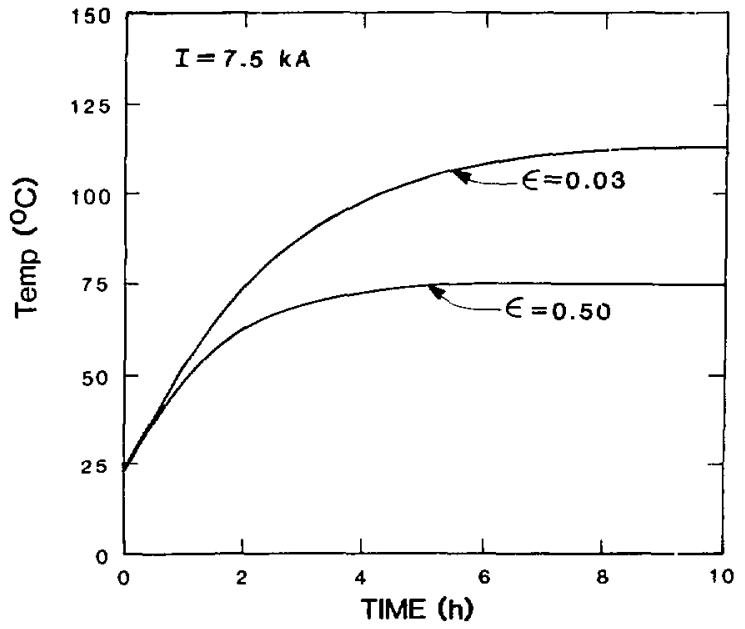

Fig. 10. Busbar temperature calculated as a function of time assuming a constant $7.5 \mathrm{kA}$ current. The bars are heated by ohmic dissipation and they are cooled by air convection and by radiation. Calculations were performed for rad'ative emissivities $\varepsilon$ of 0.03 and 0.50 . their entire lengths that can be used to pass cooling water.

The $4 / 0$ welding cables that connect the coils to the busbars are not water-cooled and are designed only for low-duty cycle operation. For higher duty cycles, watercooled flexible weiding cable is available and should be used.

\section{Electrical Shielding, Transient Suppression, and In- sulation}

The approximately 1000-turn, $0.3-\mathrm{kV}$ dc magnet coils are located $17 \mathrm{~cm}$ from the single-turn, $100-\mathrm{kV}$ thetapinch coil. Carefu! shielding design has been necessary to minimize the voltage induced by the theta pinch across the dc coil windings and the busbar feeds. The design criterion has been to limit any induced voltage to less than $1 \mathrm{kV}$. A 0.75 -in.-thick aluminum flux-excluding plate (Los Alamos Dwg. No. 33Y180799, Sheet 5) has been erected between the theta-pinch and dc coils (see Fig. 1). This plate diverts the theta-pinch magnetic flux, preventing this flux from linking the dc coils. The calculated vacuum flux surfaces generated in the absence of any flux-conserving boundaries at the dc coil locations are plotted (see Figs. $1 \mathrm{la}$ and $\mathrm{I} 1 \mathrm{~b}$ ) for condjtions without and with the flux-excluding plate and steel vacuum chambers, respectively. The plate can reduce this linking flux by nearly two orders of magnitude; however, this flux diversion is not enough because about $30 \mathrm{kV}$ could still be induced across a single pancake. Moreover, the magnetic flux at axial locations greater than about $2 \mathrm{~m}$ beyond the plate remains essentially unaffected by the presence of the plate. These calculated flux values have been confirmed by measurements made before coil installation.

To reduce the induced dc coil voltage to an acceptable level, individual or groups of up to three pancakes have been clad on all exposed surfaces. The cladding consists of electrically grounded, 0.063-in.-thick, type 1100 aluminum. Electrical joints between cladding surfaces are made using tinned copper braid and aluminum rivets. An additional 0.005-in.-thick Mylar sheet is placed between the pancake and the aluminum. The magnetic field penetration time through the cladding is several $\mathrm{ms}$, thereby reducing the induced coil voltages about another three orders of magnitude. This penetration is long enough to contain the oscillating magnetic field created by the $720-\mathrm{Hz}$ ripple current (approximately $10^{-4} \mathrm{amp}$ ac/amp dc) associate 1 with the 12 . phase rectification of the power supply. The ripple field causes the cladding to vibrate at this resonant frequency. The cladding vibrations are audible.

When one specifies that the magnetic flux at a particular boundary be zero, the voltage across the coil 

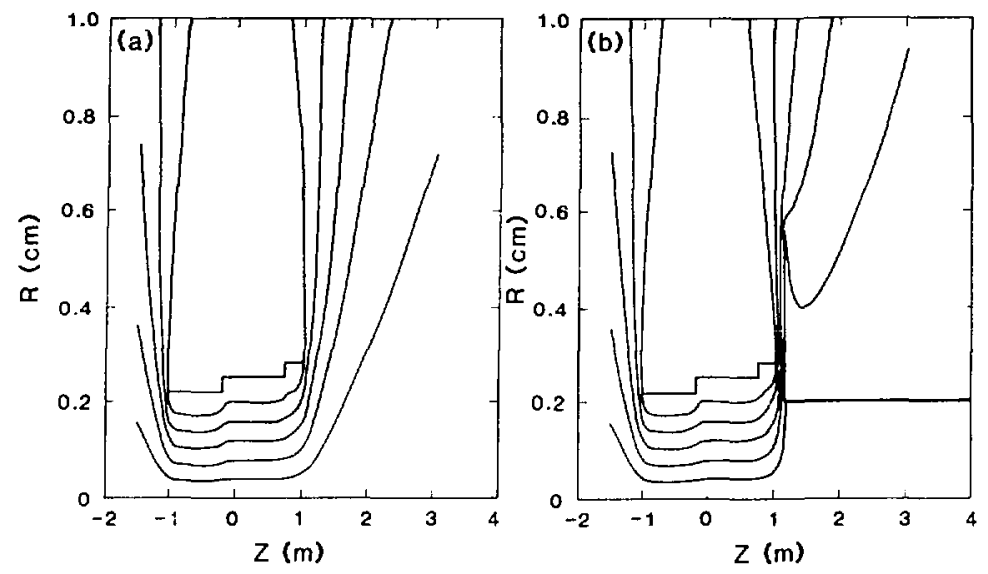

Fig. 11. Vacuum magnetic flux surfaces generated by the pulsed theta-pinch coil for cases (a) without and (b) with the presence of the flux-excluding plate and the transla ion vacuum tanks.

terminals is not necessarily zero because of the finite coil ziometry. To ensure that this voltage is minimized, a pair of metal oxide varistors (General Electric Model No. V27ZA60 and No. V18ZA40) has been installed across the terminals of each magnet coil. These components resistively damp any transient voltages and keep the coil voltage significantly less than $30 \mathrm{~V}$. Each varistor can absorb $20-40 \mathrm{~J}$ per pulse. The sum of lowvoltage transients across all of the series coils could lead to an unacceptably large voltage across the power supply output. To suppress these transients, a 320-V, 300-J varistor (General Electric Model No. V320HE300) is placed across the busbars near the free-wheeling diode. Two $0.47-\mu \mathrm{F}, 600-\mathrm{V}$ capacitors are also placed in parallel across the busbars near the same location.

Insulation to prevent electrical breakdown is necessary in the $15-\mathrm{cm}$ gap that separates the thetapinch coil from the grounded flux-excluding plate. Three nested, high-density polyethylene "hats" (Los Alamos Dwg. No. 33Y180797) are placed with their 36-in.-diam brims in the gap and their 10-in.-long crowns (with ends cut off) inserted between the thetapinch coil and the quartz discharge tube. The minimum thickness of each hat is 0.25 in. They have been fabricated using a relatively inexpensive ( $\$ 35 / \mathrm{hat})$ thermovacuum forming process by A \& W Plastics, Denver, Colorado, which will retain the mo!ds and store them until March 1988. Inserted around and in between the hat brims are 25 shects of 72 -in. $x$ 72-in., 0.010 -in.-thick Mylar.

\section{E. Structural Supports}

Each dc magnet weighs approximately $500 \mathrm{lb}$. The coils are installed onto FRX-C/T using crane hoists (Los Alamos Dwg. 33Y 180794). The pancake base fits inside a custom-designed carriage (Los Alamos Dwg. No. 33 Y 180775) that rides on bearings along the vacuum tank support stand (see Sec. III.E).

An axial compression force of up to 40 tons can be applied to the magnets by the 10-kG B-fields. The pancakes are reinforced against collapse by seven 5-in.diam aluminum and brass spacers placed in every pancake gap (Los Alamos Dwg. No. 33Y180806). Four of these spacers are adjustable, whereas the other three are cust ${ }^{\text {ror }}$ fit around the 2-in.-diam stainless steel support shatts that span the length of the coil set.

\section{VACUUM HARDWARE}

The construction of FRX-C/T has required major alte:ations and additions to the vacuum hardware. $A$ $40-\mathrm{cm}$ bore, up to $6.3-\mathrm{m}$-long stainless steel vacuum chamber has been added. The existing quartz discharge tube has been modified and the vacuum pumps moved. The theta-pinch coil ground plane has also been changed. 


\section{A. Stainless Steel Vacuum Tanks}

The translation region vacuum vessel consists of up to five 4-ft-long modules, each consisting of a 16-in.o.d., 0.188-in.-wall, type 304 stainless steel pipe (see Fig. 12 and Los Alamos Dwg. N). 33Y180772). There are 28 diagnostic ports in each module (twelve 6-in.-diam and sixteen 2.75-in.-diam stainless steel conflat flanges) welded around holes drilled through the tank walls at 6 -in. axial intervals and at every $90^{\circ}$ azimuthal position. Because of radial space limitations created by the 20 -in.i.d. dc magnet coils, the 6-in. conflats are recessed about $0.625 \mathrm{in}$. inside the tank. Welded cnto each module ind are 18-in.-o.d. stainless steel flanges. Vacuum seals between modules are made using 16.510-in.-o.d., 16.100in.-i.d. aluminum O-rings (Model No. HN200, manufactured by Helicoflex Co., Boonton, New Jersey).

Before installation the modules are vacuum prepared by the following procedure: (1) vapor degreasing in trichloroethylene, (2) electropolishing, (3) ultrasonic cleaning and rinsing with detergent (Alconox) and distilled water, (4) conflat-flange cover installation, and (5) leak checking. Los Alamos Group MST-6 (electrochemistry section) performed the first two steps and Group CTR-3 performed the remainder. An if glow discharge cleaning system has been considered. The base pressure i $r$ the stainless steel-quartz chambers (see below) is about $4 \times 10^{-8}$ torr, a value about equal to that in FRX-C, which contained only half of the current volume.

Diagnostic and end flanges were welded before any vacuum preparation. As a result, impurities from the coated surface of the steel pipe became partially impregnated into the welds. This dirt could be only partially removed by electropolishing. To effectively clean these welds, the modules were precleaned by glassbead blasting before the five-step procedure above, but this problem could have been prevented if the dirty pipe had been degreased and electropolished before being welded.

The welds of the vacuum tanks were made using type 308 stainless steel rod. Type 300 series stainless steels are known to undergo phase transitions to ferromagnetic materials as a result of welding. This added permeability car be reduced by annealing the steel in a vacuum furnace. Although this procedure was considered, it has not been followed because of the small (about $0.5-\mathrm{G}$ ) magnetic field errors caused by these welds (see Sec. II.B and Fig. 6). Metallurgists recommend using type 2169 stainless steel for more austenitic welds.

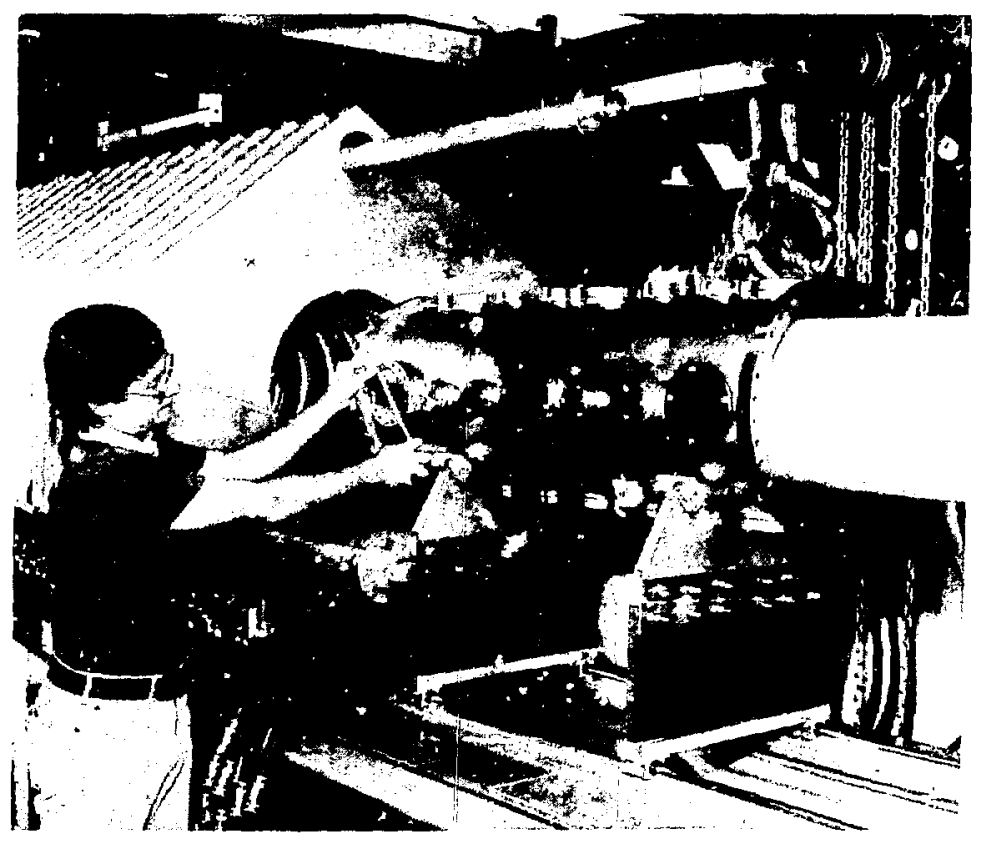

Fig. 12. Photograph of a single 4-ft-long translation region vacuum tank module. In this photo, the cantilevered Hall probe holder penetrates one end of the module. The cladded dc magnet coils appear in the background. 


\section{B. Quartz Discharge Tube}

The theta-pinch vacuum chamber consists of a 297-cm-long, 41.7-cm-o.d., 0.45-cm-wall, fused silica tube (see Fig. 13 and Los Alamos Dwg. No. 33Y180523). A tube previously procured for FRX-C was cut to the above length by Los A.tamos MEC-5 Shop No. 48 (SM-287, Room 101) using a diamond saw. A new tube of proper dimensions has also been procured from. Herreus-Amersil, Sayerville, New Jersey. Two 0.75 -in.-diam puff valve ports have been drilled at nearly opposite sides in the quartz tube at the center position of the theta-pinch coil, using an ultrasonic drilling machine with a diamond-tipped hole-cutting bit, by a ceramics shop (Los Alamos Shop 47) located near the MST-6 facilities. As in the FRX-C experiment, vacuum seals between the quartz and stainless steel supports on both ends are made with a 16.375-in.-i.d., 0.413 -in.-thick Viton O-ring. The quartz tube-stainless steel translation region interface (Los Alamos Dwg. NG. 33Y180799) is supported by the aluminum flux-excluding plate (Sec. II.D).

\section{Vacuum Stand and Pumps}

For FRX-C/T, the FRX-C vacuum stand (see Fig. 14 and Los Alamos Dwg. No. 33Y 180567) has been modified and moved to the opposite (south) end of the quartz discharge tube. The stand is electrically connected to the ground plane, which spans the entire length of the device and follows the diagnostic conduits in a trench at the south end of the experiment. Both end supports for the quartz tube are grounded. The vacuum stand is supported against the 1-ton atmospheric axial force by an electrically isolated steel structure (Los Alamos Dwg. No. 33Y 180816) that connects to enforced pillars supporting the theta-pinch collector plates. Without these reinforcements, an unacceptably large axial deflection of the vacuum stand and the quartz discharge tube occurs when the chambers are evacuated (see Sec. III.E). (The phenolic rods formerly used in FRX-C to counteract this force could no longer be used because they would have interfered with the electrical insulation placed on the north end of the quartz tube.)

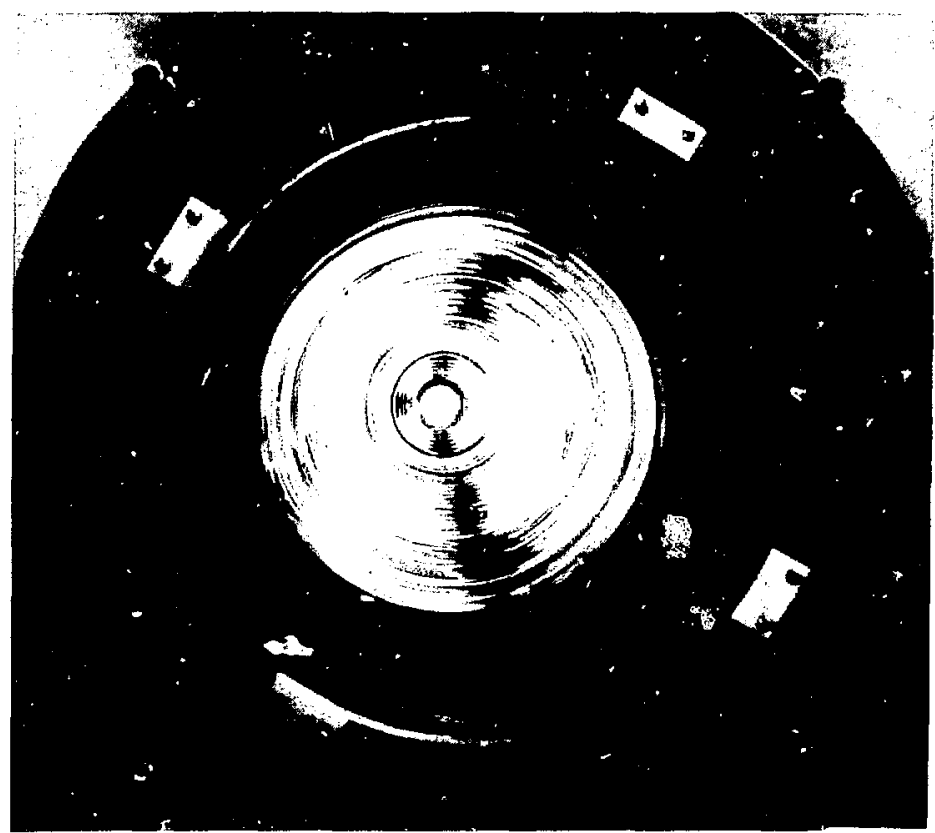

Fig. 13. Photograph of the $40 \mathrm{~cm}$-bore vacuum chamber. The 3-m-long quartz discharge tube (foreground) is located inside the theta-pinch coil. The stainless steel translation region modules appear in the background. 


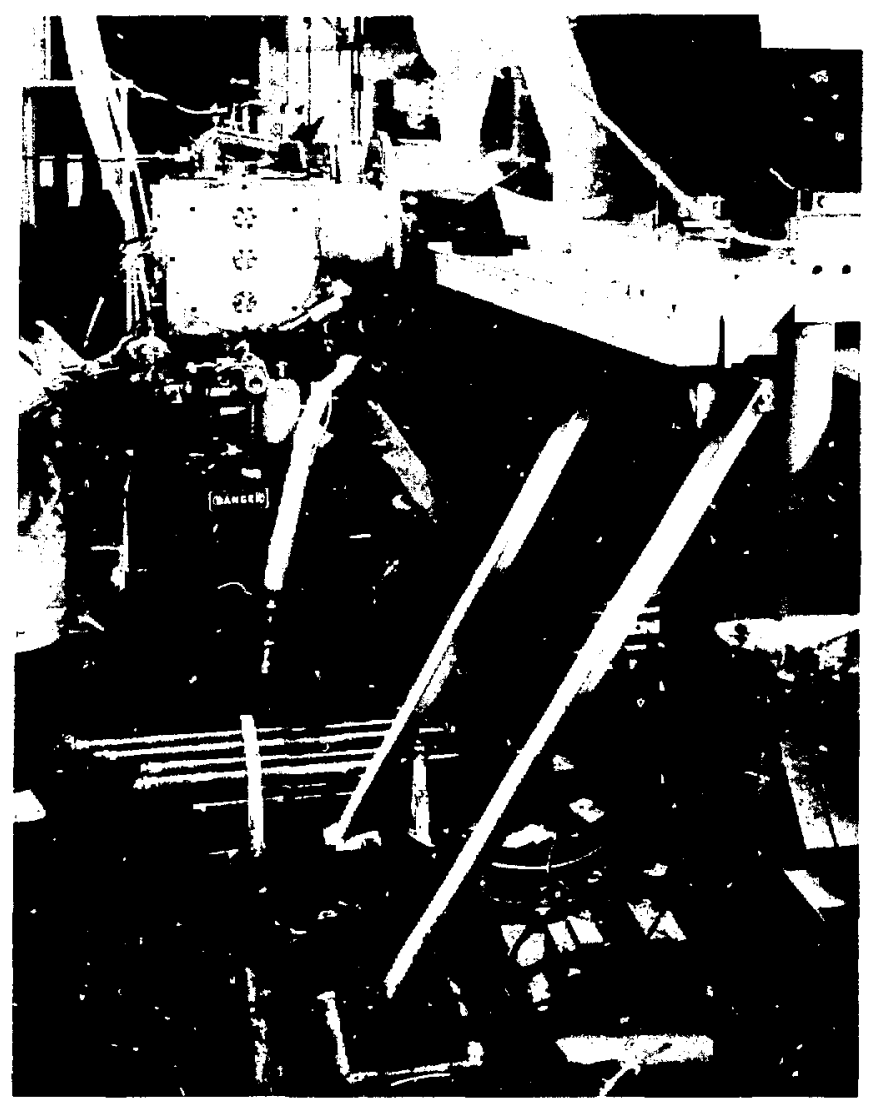

Fig. 14. Photograph of the vacium stand and tise upstream (south) end suppor structure.

The vacuum pumps, control system, and gauges arc the same used in FRX-C. The pumps and gauges have been moved with the vacuum stand, which required rerouting all of the electrical and pneumatic lines that connect the control racks and the computer inputs and outputs to the vacuum stand. A head for a residual gas analyzer (UTHE Technology International, Model No. $100 \mathrm{C}$ ) has also been added to the vacuum stand.

\section{Gas Fill Systems}

Two modes of deuterium gas filling before plasma discharge are possible. The same "static" fill system used in FRX-C has been connected, in which gas from a several-torr, $54-\mathrm{cm}^{3}$ plenum is transferred to the main vacuum chamber before starting the 90-s charge sequence. Using this static fill system, FRCs can be formed and translated through the 5- to 20-mtorr pressure $D_{2}$ neutral gas background. Translation through these neutrals can result in an unacceptably large plasma energy loss due to charge exchange, excitation, dissociation, and ionization.' To minimize these losses, a puff gas-injection system has been installed. Deuterium is puffed into the quartz tube 1-3 ms before the plasma discharge. This gas is localized in the source and the pressure is significantly reduced in the downstream translation region.

Puff valves developed for the CTX experiment at Los Alamos are used (Los Alamos Dwg. No. 33Y180511). These valves have beeil modified to include a larger plenum volume of 0.71 or $1.45 \mathrm{~cm}^{3}$. Two modes of puff gas injection are possible. Gas may be injected side-on frorn two valves $\left(0.71-\mathrm{cm}^{3}\right.$ plenums) mounted $\mathrm{s}$ opposite sides at the theta-pinch coil center. The valves are physically supported by a structure connected to the theta-pinch coil (Los Alamos Dwg. No. 33Y 180770) and are mounted to the discharge tube by a 1-in.-diam stainless steel welded bellows and attached to a 1-in.o.d., 0.063-in.-wall, 6-in.-long, quartz tubulation that is epoxied to the discharge tube using Torr-Seal (see Fig. 15). This sealant is applied only to the outer surface of 


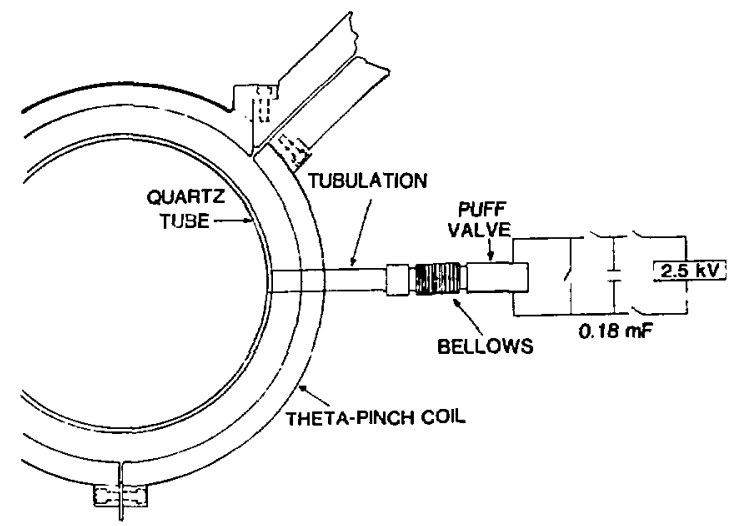

Fig. 15. Schematic diagram of the puff valve system.

the quartz discharge tube to prevent any contact between the plasma and the epoxy. The other mode of puffing uses end-on injection from a valve with a 1.45$\mathrm{cm}^{3}$ plenum mounted on axis at the south end (i.e., on the vacuum stand) of the device.

Transient neutral gas distributions are measured using a CK5702 tetrode, fast-ionization gauge. ${ }^{8}$ Typical measured $p(z, t)$ axial $D_{2}$ pressure profiles from side-on injection are plotted in Fig. 16.

The solenoid coil of each puff valve is driven by an ignitron-switched, $180-\mu \mathrm{F}$ capacitor charged to $1.4 \mathrm{kV}$. The high-voltage and ground connections of this circuit

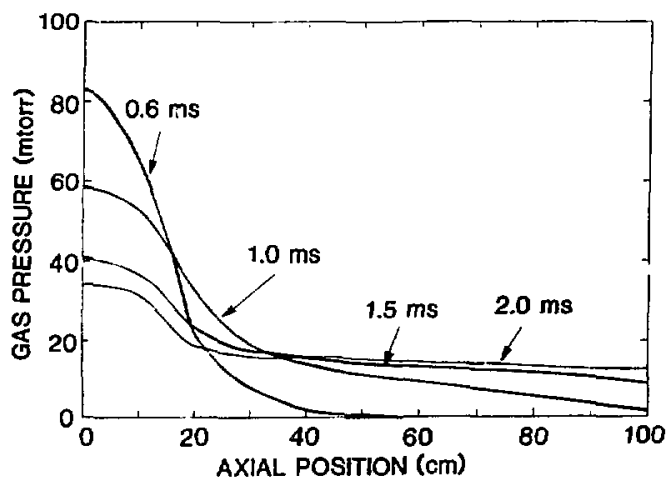

Fig. 16. Axial $D_{2}$ gas distributions measured on axis for side-on gas injection. are removed before the discharge to prevent any current loops baing created by the plasma. Microswitches positively sense this disconnection during the final $10 \mathrm{~s}$ of the charge sequence; otherwise an abort is issued by the computer, preventing the discharge.

\section{E. Support Structures}

The translation region vacuum tanks and dc magnet coils rest upon a support table (see Fig. 17 and Los Alamos Dwg. No. 33Y180775), which is made from type 6061 aluminum plates, I-beams, and channel. This table is electrically isolated from the floor by phenolic plates and is grounded at the south end by the thetapinch ground plane. There are four separate tables ranging in length from 4 to $16 \mathrm{ft}$. The second table from the theta-pinch (south) end rests on a pair of 1 -in.-diam rails and this entire unit can be translated up to $5-\mathrm{ft}$ in the direction transverse to the machine axis.

Mounted along the entire length of these tables are two 0.625 -in.-diam bearing shafts, spaced 18 in. apart, along which the yacuum tank and dc coil supports ride. The vacuum tank supports (see Fig. 12 and Los Alamos Dwg. No. 33Y 180775) consist of a type 6061 aluminum base that houses the bearings. Attached to this base is a phenolic support that provides electrical isolation and connects to the 4-ft-long stainless tank modules with aluminum clamps. Some of the tank supports have been modified. The aluminum bases have been directiy connected to the dc coil supports.

In the original design, the vacuum chambers were to be supported against the 1-ton atmospheric axial compressional force by the vacuum stand on the south end without the additional reinforcements and by the aluminum flux-excluding plate on the north end. This configuration was tried, but when the chambers were evacuated, the aluminum plate and the vacuum stand deflected sufficiently to cause an unacceptably large axial deflection (>0.125 in.) of the quartz discharge tube. Vacuum stand supports (Sec. III.C) have been added and an additional 0.75 -in.-thick aluminum plate has been placed at the north end (see Fig. 18). $T$. . s plate is reinforced with aluminum channel and connects the vacuum chambers to the support tables and the upper deck through the crane hoist I-beams. Electrical ground loops are avoided using phenolic breaks. When the vacuum chambers are evacuated, a 0.010-in. axial deflection of the discharge tube occurs. 


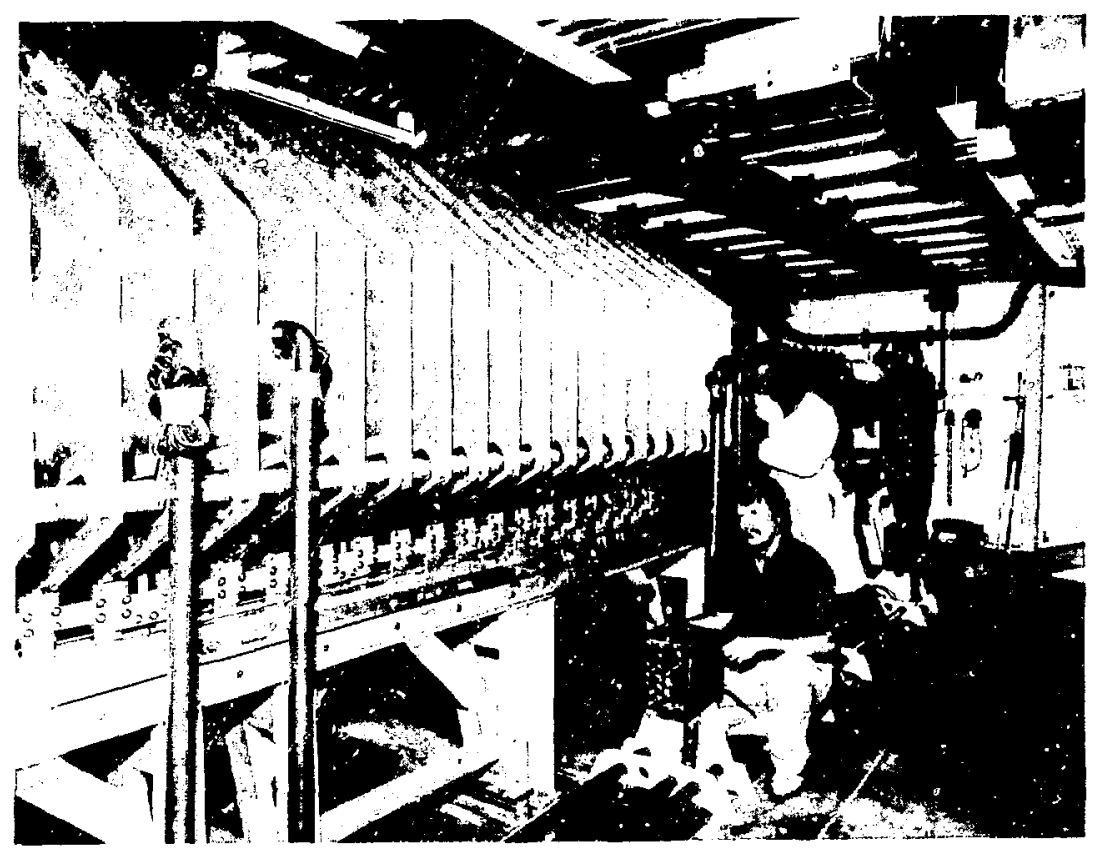

Fig. 17. Photograph of the support tables and dc magnet coils.

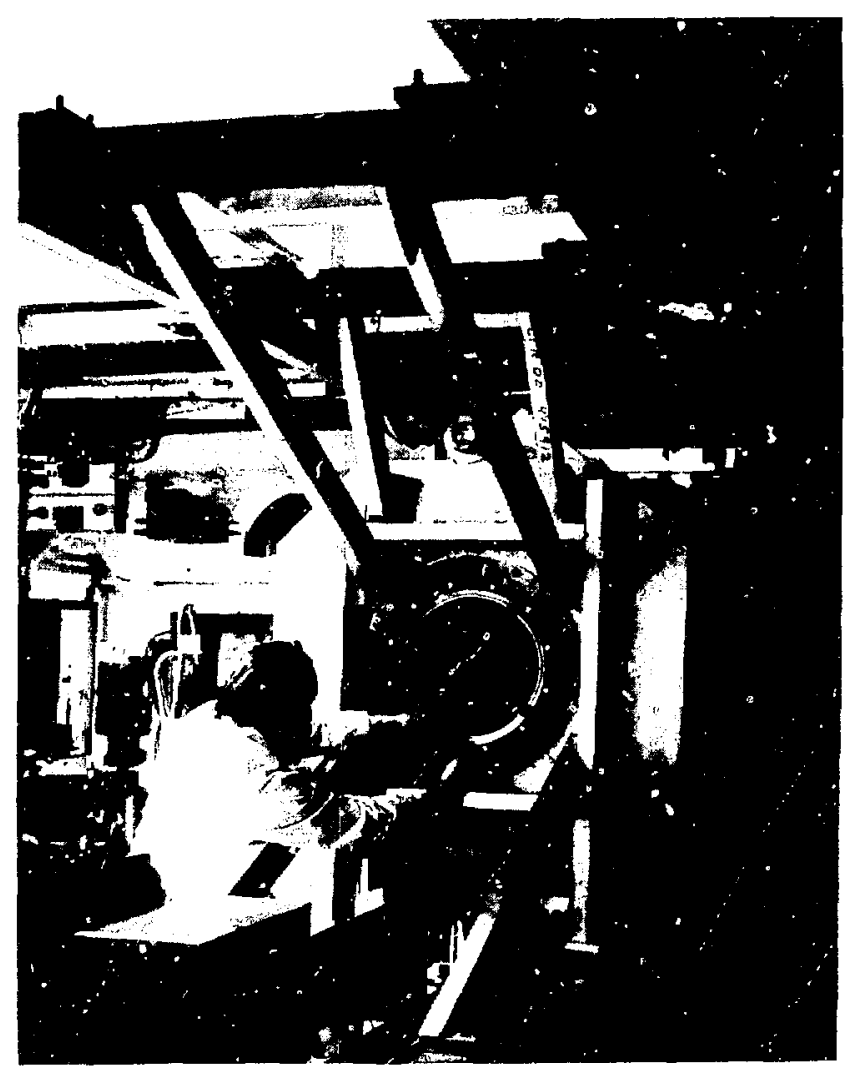

Fig. 18. Photograph of the downstream (north) end support structure. 


\section{ACKNOWLEDGMENTS}

The design, fabrication, and construction of the FRXC/T hardware required an intensive team effort. Specific design work was performed by T. A. Carroll and E. J. Yavornik (mechanical engineering), R. E. Chrien and E. G. Sherwood (puff gas injection), J. C. Cochrane, Jr. and R. W. Kewish, Jr. (cooling), Rita Gribble (2.5-MW dc power system and magnet thermal sensors), P. L. Klingner (computer control system and software), and K. F. McKenna (vacuum). All of these designs were improved by the many suggestions of W. T. Armstrong, R. R. Bartsch, R. F. Gribble, R. K. Linford, R. E. Siemon, and M. Tuszewski (CTR Division), and E. J. Schneider and E. D. Bush (MP Division). The outstanding technical support received from E. R. Mignardot, B. G. Anderson, W. R. Doty, E. L. Duran, M. M. Harper, G. N. Lowry, D. R. Martinez, J. P. Montoya, F. R. Olivas, D. Ortega, J. S. Quintana, R. J. Sanchez, R. Vigil, V. P. Vigil, and $D$. J. Wade and the fabrication of the mechanical parts by R. H. Barnes, J. B. Baca, J. F. Griffin, G. R. Harper, H. D. Reed, T. Santillanes (MEC-5 Shop 48), and W. Ciddeo (Shop 8) are gratefully acknowledged. The drafting by R. Robinson, P. Scritchfield, and P. Witt is appreciated.

\section{REFERENCES}

1. R. E. Siemon, W. T. Armstrong, R. R. Bartsch, R. E. Chrien, J. C. Cochrane, R. W. Kewish, P. L. Klingner, R. K. Linford, K. F. McKenna, D. J. Rej, E. G. Sherwood, and M. Tuszewski, "Experimental Studies of Ficld-Reversed Configuration Confinement in FRX-C," in Plasma Physics and Controlled Nuclear Fusion Research 1982 (International Atomic Energy Agency, Vienna, 1983), Vol. II, pp. 283-292.
2. D. J. Rej, W. T. Armstrong, R. E. Chrien, P. L. Klingner, R. K. Linford, K. F. McKenna, R. D. Milroy, E. G. Sherwood, R. E. Siemon, and M. Tuszewski, "Translation of Field-Reversed Configurations in the FRX-C/T Experiment," in Proc. 6th U.S. Japan Symposium on Compact Toroid Research (Princeton Plasma Physics Laboratory, Princeton, New Jersey, 1984).

3. R. W. Kewish, Ir., R. R. Bartsch, and R. E. Siemon, "Engineering Design of the FRX-C Experiment," Proc. 9th Symposium for Engineering Problems of Fusion Research (Publication No. 81CH1715-2, IEEE, New York, 1981), pp. 1751-1754.

4. R. W. Kewish, Jr., and D. J. Rej, "Summary of Transient High-Voltage Calculations for the FRX-C Experiment," Los Alamos National Laboratory report LA-9380-MS (June 1982).

5. e.g., J. H. Brownell, H. Dreicer, R. F. Ellis, and J. C. Ingraham, "Influence of Intense ac Electric Fjelds on the Electron-Ion Collision Rate in a Plasma," Phys. Rev. Lett 33, 1210 (1974).

6. J. Rand, "Regulation of $2.5 \mathrm{MW}$ dc Power Supply to $0.01 \%$," Ios Alamos Scientific Laboratory report LA-4964-MS (September 1972).

7. D. J. Rej, "Interaction of the Neutral Deuterium Flux With a Field-Reversed Configuration," in Proc. 6ih U.S.-Japan Symposium on Compact Toroid Research (Princeton Plasma Physics Laboratory, Princeton, New Jersey, 1984).

8. E. A. Valsamakis, "Ionization Gauge for Transient Gas Pressure Measurements," Rev. Sci. Instr. 37, 1318 (1966). 


\section{APPENDIX}

\section{RELATED ENGINEERING DRAWINGS FOR FRX-C/T DEVICE*}

Part:

Puff Valve System

Quartz Nischarge Tube

Vacuum Pump Stand

Theta-pinch Coils

dc Pancake Coil

Experimental Room Layout

Puff Valve Supports

4-ft-long SS Vacuum Tanks

Translation Region Support Structure

Crane Hoists

Polyethylene Insulating Hats

Quartz-Stainless Interface

2.5 MW dc Busbars

0-10 m $\Omega$ Shunt Resistors

Magnet Cooling Hose Assembly

Cooling Manifolds

dc Magnet Support/Spacers

South End Support Structure

Hall Probe Holder No. 1

Hall Probe Holder No. 2

Fiberoptic Transceivers
Los Alamos

Drawing Number

$33 \mathrm{Y} 180511$

$33 \mathrm{Y} 180523$

$33 Y 180567$

$33 Y 180759$

$33 Y 180762$

$33 Y 180767$

$33 Y 180770$

$33 Y 180772$

$33 Y 180775$

$33 Y 180794$

$33 Y 180797$

$33 \mathrm{Y} 180799$

$33 Y 180800$

$33 Y 180801$

$33 Y 180803$

$33 Y 180805$

$33 Y 180806$

$33 \mathrm{Y} 180816$

$33 Y 180823$

$33 Y 180852$

$45 Y 123941 / 6$

*Drawings available from D. J. Rej, Group CTR-3, Los Alamos National Laboratory. 